\title{
COVID-19 Vaccines for the low-income Countries; challenges and the way forward
}

\author{
Purushottam Adhikari 1* (D), Sangeeta Poudel ${ }^{2}$, Asmita Itani ${ }^{3}$, \\ Swotantra Gautam ${ }^{4}$, Saroj Adhkari Yadav ${ }^{5}$
}

\author{
'Department of Neuropsychiatry, Nepalese Army Institute of Health Sciences, ${ }^{2}$ Department of Emergency,Banepa Hospital, \\ ${ }^{3}$ Department of Emergency, GP Koirala National Centre for Respiratory Diseases, ${ }^{4}$ Department of Emergency, \\ B.P.Koirala Institude of Health Sciences, ${ }^{5}$ Department of Emergency, Patan Academy of Health Sciences
}

\begin{abstract}
The vaccine rollout has started for the health workers as well as common people all around the world. The production has been going on rapidly, but the poor and low income countries are still lagging behind to get in the vaccine race and have their people vaccinated. A group of several international non-governmental organizations has warned about $90 \%$ of people in 67 low-income countries to have a low chance of being vaccinated in 2021 due to more than a necessary number of vaccines reserved by developed countries. COVAX program, co-led by Gavi, the Vaccine Alliance, along with the World Health Organization (WHO) and the Coalition for Epidemic Preparedness Innovations (CEPI) has raised rays of hope but it's still long way to go. Vaccine hesitancy among the public, logistics and storage difficulty and emergence of new variants has emerged as potential challenges for COVID-19 vaccination in developing countries.
\end{abstract}

Key words: COVID-19 vaccines, low-income countries, pandemic, public health, SARS-CoV2, vaccine hesitancy

\section{*Correspondence:}

Dr. Purushottam Adhikari

Resident, Department of Neuropsychiatry

Nepalese Army Institute of Health Sciences,

Kathmandu, Nepal

Email: puru.ad12@gmail.com

Phone: +977-9841066077

To cite: Adhikari P, Poudel S, Itani A, Gautam

S, Yadav SA. COVID-19 Vaccines for the lowincome Countries; challenges and the way forward. JGMC Nepal. 2021;14(1):78-0.

DOI: $10.3126 /$ jgmcn.v14i1.38081

\section{INTRODUCTION}

Scientists and researchers all over the world are working hard for identifying the potential vaccine candidates and some of them have already been identified. ${ }^{1} \mathrm{~A}$ significant number of countries have already started to vaccinate the health workers and common people. Despite the positive rays of hope for combating this pandemic, third world countries with low income are still striving for days to come for being vaccinated.

People's Vaccine Alliance, a group of several international non-governmental organizations has warned about $90 \%$ of people in 67 low-income countries to have a low chance of being vaccinated in 2021 due to more than a necessary number of vaccines reserved by developed countries, and also due to pharmaceutical corporations not sharing their intellectual property.Rich countries have bought $53 \%$ of the eight most promising vaccines with only $14 \%$ of the world's population. This will leave common people and even health workers unvaccinated in low-income countries which clearly shows the disparity in the distribution of the vaccine. ${ }^{2}$

COVAX Initiatives

COVAX program, co-led by Gavi, the Vaccine Alliance, along with the World Health Organization (WHO) and the Coalition for Epidemic Preparedness Innovations (CEPI), is a global initiative working with 
different stakeholders like governments, manufacturers and financiers to secure COVID-19 vaccines through a global, pooled mechanism and make them available to people in both lower-income and higher-income countries. ${ }^{3}$ According to the COVAX global supply forecast assuming the available funding, it is expected that 1.8 billion doses of vaccine are to be available for 92 economies of the Gavi COVAX Advanced Market Commitment (AMC) in 2021 corresponds to $27 \%$ of the AMC populations. Among these 1.3 billion of the doses will be available at no cost to their governments. ${ }^{4}$

World Health Organization has also initiated the formation of Access to COVID-19 Tools (ACT) Accelerator to facilitate the development, production as well as equitable access to COVID-19 tests, treatments, and vaccines all over the world in collaboration with the global health organizations and other stakeholders. ${ }^{5}$

\section{When will they really get the vaccines?}

The vaccine by COVAX initiatives will be delivered in proportion to the populations. South-East Asia and Africa will be the regions receiving more than one billion by the end of 2021. The COVAX global supply forecast estimates that the supply of the vaccines would be started from the first quarter of 2021 and it expects to increase month by month this year. However, the challenges of funding, local regulatory approval, logistics, and readiness of the countries are always there for achieving the estimated target. ${ }^{4}$ The ongoing trials and emergency approvals of several vaccines in India and China has raised the hope for the South-EastAsian regions that don't have the ability to produce and vaccinate their population on their own. ${ }^{1}$

\section{Challenges for the developing countries}

Vaccine hesitancy is a potential obstacle for global vaccination, more in developing countries due to misinformation, winging of conspiracy theories, and inadequate awareness among common people. It has emerged as a potential challenge in the fight against COVID-19. ${ }^{6}$ In a French survey done among people with poor compliance of recommended vaccinations, low education level and female gender were more likely to refuse the vaccine. ${ }^{7}$ Communication campaigns and proactive actions from the governing bodies can be of help to reduce vaccine hesitancy and run the vaccination campaign effectively.

Emerging new SARS-CoV-2 variants has raised a concern on effectiveness of ongoing vaccination as if the immunity produced works against new variants or not. This could be challenge in upcoming days in vaccination against COVID-19 and further surveillance and rigorous studies are required. ${ }^{8}$

Ultra cold chains and short shelf-lives of some of the vaccines are other significant hindrances in the developing countries for the vaccine campaigns as the facility for storage and transport may not be available. ${ }^{9}$ So, the vaccines for developing countries should be the one requiring minimal logistics so that it could be stored and transported as in the similar way other vaccines in national immunization program.

\section{CONCLUSION}

Though high-income countries have better accessibility to the vaccines and can run the vaccination program smoothly, the end of a pandemic is not coming sooner if the same doesn't apply to the middle and low-income countries. This is only possible if the vaccine manufacturers acknowledge the appeal by Vaccine Alliances and share their intellectual property and commit to an open license enabling the expansion of vaccine development and accessibility. The COVAX program has raised some hope for low and middle-income countries for being able to vaccinate at least their health workers, and then elderly and vulnerable groups as well on a priority basis by the end of this year.

Along with attention on making vaccine accessible to the low-income countries with the increment of vaccine production, the shift of attention should also be made regarding the roll-out of the available vaccines since many low-income countries lack reliable infrastructure, electricity supply, and cold chain facility which are crucial to secure the effectiveness of the vaccine. The political stability of the country as well plays a crucial role in vaccine distribution and on the sustainability of the vaccination program. Misinformation leading to vaccine hesitancy as well is the burning issue in selected population groups of many countries.

\section{SOURCE OF FINANCIAL SUPPORT: None}

\section{CONFLICTS OF INTEREST:}

No potential conflict of interest to declare.

\section{REFERENCES}

1. The COVID-19 vaccine race - weekly update. Gavii, The vaccine alliance. 2021. Available from: https://www.gavi.org/ vaccineswork/covid-19-vaccine-race [Accessed $10^{\text {th }}$ February2021]. 
2. Dyer 0. Covid-19: Many poor countries will see almost no vaccine next year, aid groups warn. BMJ. 2020;371:m4809. DOI: 10.1136/bmj.m4809 PMID: 33310819.

3. Anuradha Gupta. Protecting Lower-Income Countries with COVID-19 Vaccines Requires Global Solidarity Gavii, The vaccine alliance. 2021. Available from: https://www. gavi.org/vaccineswork/protecting-lower-income-countries-covid-19-vaccines-requires-global-solidarity [Accessed $7^{\text {th }}$ February2020].

4. Priya Joi, James Fulker. COVAX Supply Forecast reveals where and when COVID-19 vaccines will be delivered. Gavii, The vaccine alliance. 2021. Available from: https://www.gavi. org/vaccineswork/covax-supply-forecast-reveals-wherewhen-covid-19-vaccines-will-be-delivered [Accessed 2 $2^{\text {nd }}$ February 2020].

5. What is the ACT-Accelerator. World Health Organization. 2020. Available from: https://www.who.int/initiatives/ act-accelerator/about [Accessed10th February 2020].

6. Khan Y, Mallhi T, Alotaibi N, Alzarea A, Alanazi A, Tanveer $\mathrm{N}$, et al. Threat of COVID-19 Vaccine Hesitancy in Pakistan:
The Need for Measures to Neutralize Misleading Narratives. Am J Trop Med Hyg. 2020;103(2):603-4. DOI: 10.4269/ajtmh.20-0654 PMID: 32588810.

7. Schwarzinger $M$, Watson V, Arwidson P, Alla F, Luchini S. COVID-19 vaccine hesitancy in a representative working-age population in France: a survey experiment based on vaccine characteristics. The Lancet Public Health. 2021;6(4):e210-e221. DOI: 10.1016/S2468$\underline{\text { 2667(21)00012-8 }}$

8. Bian L, Gao F, Zhang J, He Q Mao Q Xu M, et al. Effects of SARS-CoV-2 variants on vaccine efficacy and response strategies. Expert Rev Vaccines. 2021 Apr 14:1-9. DOI: 10.1080/14760584.2021.1903879 PMID: 33851875.

9. Wouters OJ, Shadlen KC, Salcher-Konrad M, Pollard AJ, Larson HJ, Teerawattananon $\mathrm{Y}$, et al. Challenges in ensuring global access to COVID-19 vaccines: production, affordability, allocation, and deployment. Lancet. 2021 Mar 13;397(10278):1023-1034. DOI: 10.1016/S01406736(21)00306-8. PMID: 33587887. 